\title{
Space ravioli, nuclear explosions and a synthetic sun
}

March's sharpest science shots, selected by Nature's photo team.

31 March 2017

\section{Synthetic sun}

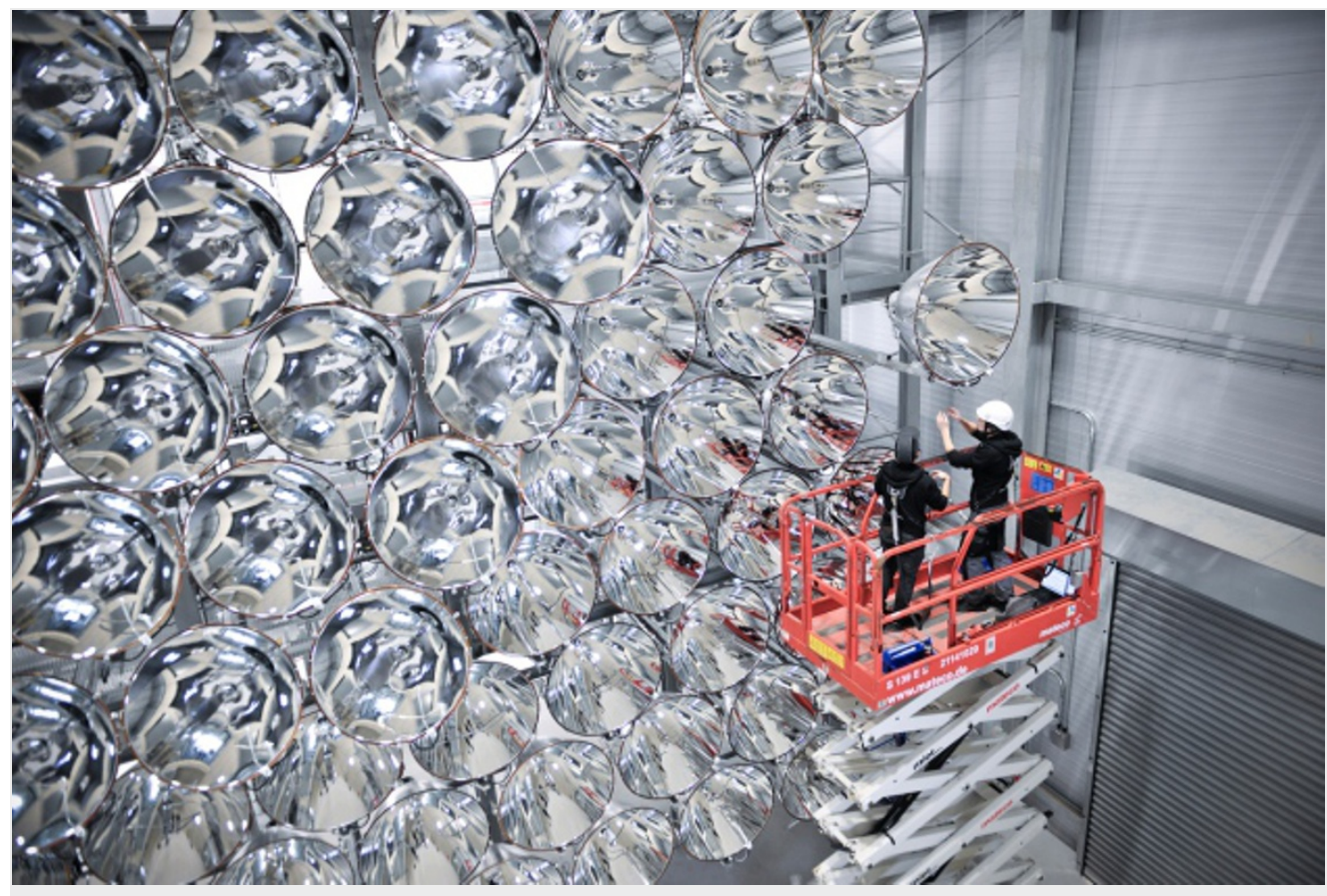

Markus Hauschild

The German Aerospace Center unveiled what it says is the world's largest artificial sun on 23 March. Using 149 high-powered lamps, the Synlight facility in Jülich can create a spot where temperatures reach 3,000

${ }^{\circ} \mathrm{C}$. It will be used for research on producing fuels with solar power.

\section{Secret snaps}

Lawrence Livermore National Laboratory physicist Greg Spriggs has been trying to save thousands of films taken of US nuclear weapon tests between 1945 and 1962. The recordings had been locked in secure vaults across the country. He has so far found around 6,500 of these top-secret films, and on 14 March the California-based lab released a set of them that have now been declassified. 


\section{Space ravioli}

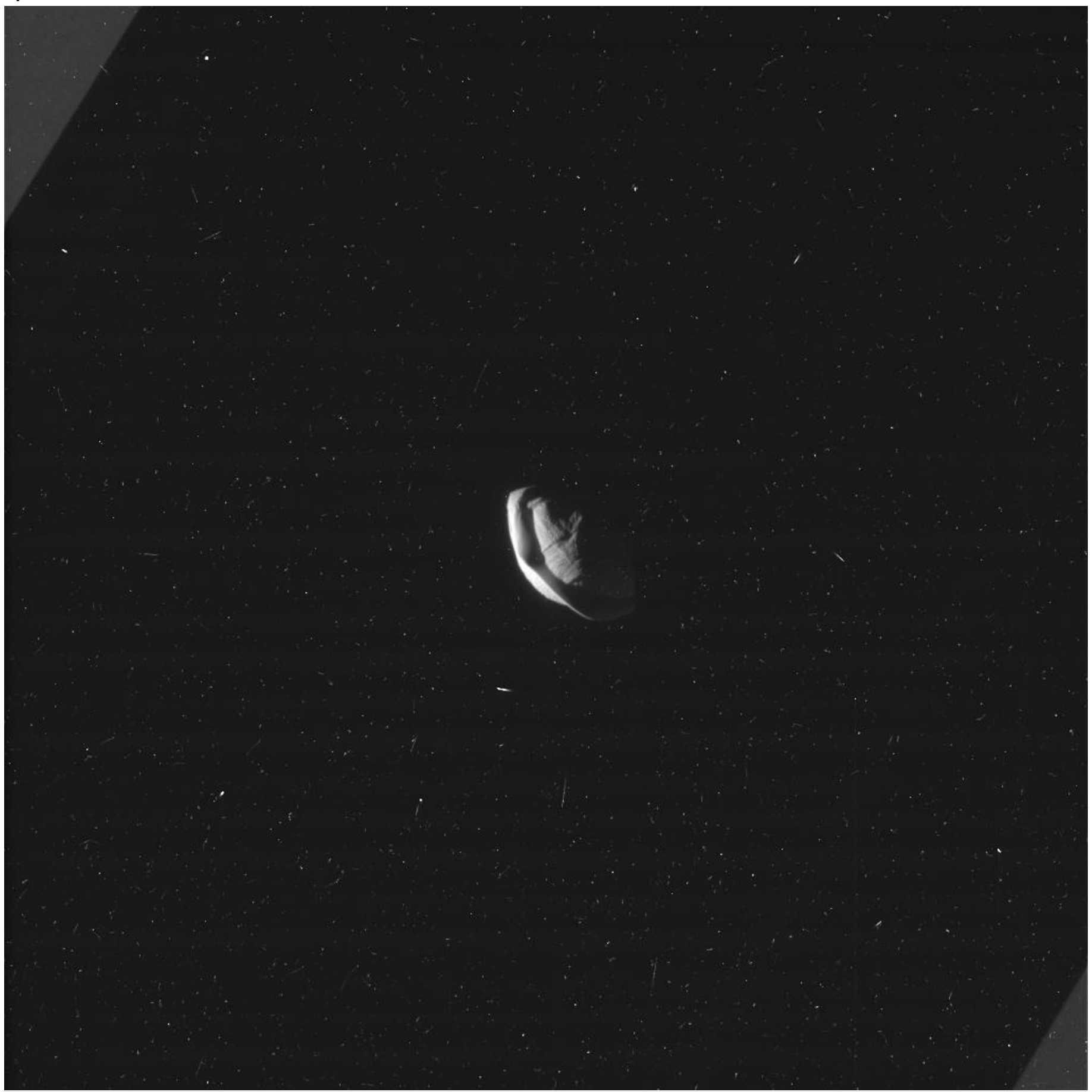

NASA/JPL-Caltech/Space Science Institute/K. Walbot/S. Samochina

On 7 March, NASA's Cassini spacecraft snapped a series of images of Saturn's unusually shaped moon, Pan. Taken from a distance of 24,572

kilometres, the shots are the closest ever taken of the satellite. They clearly show the skirt of material, probably accreted from surrounding dust, that makes it look like a piece of ravioli.

\section{Six years later}




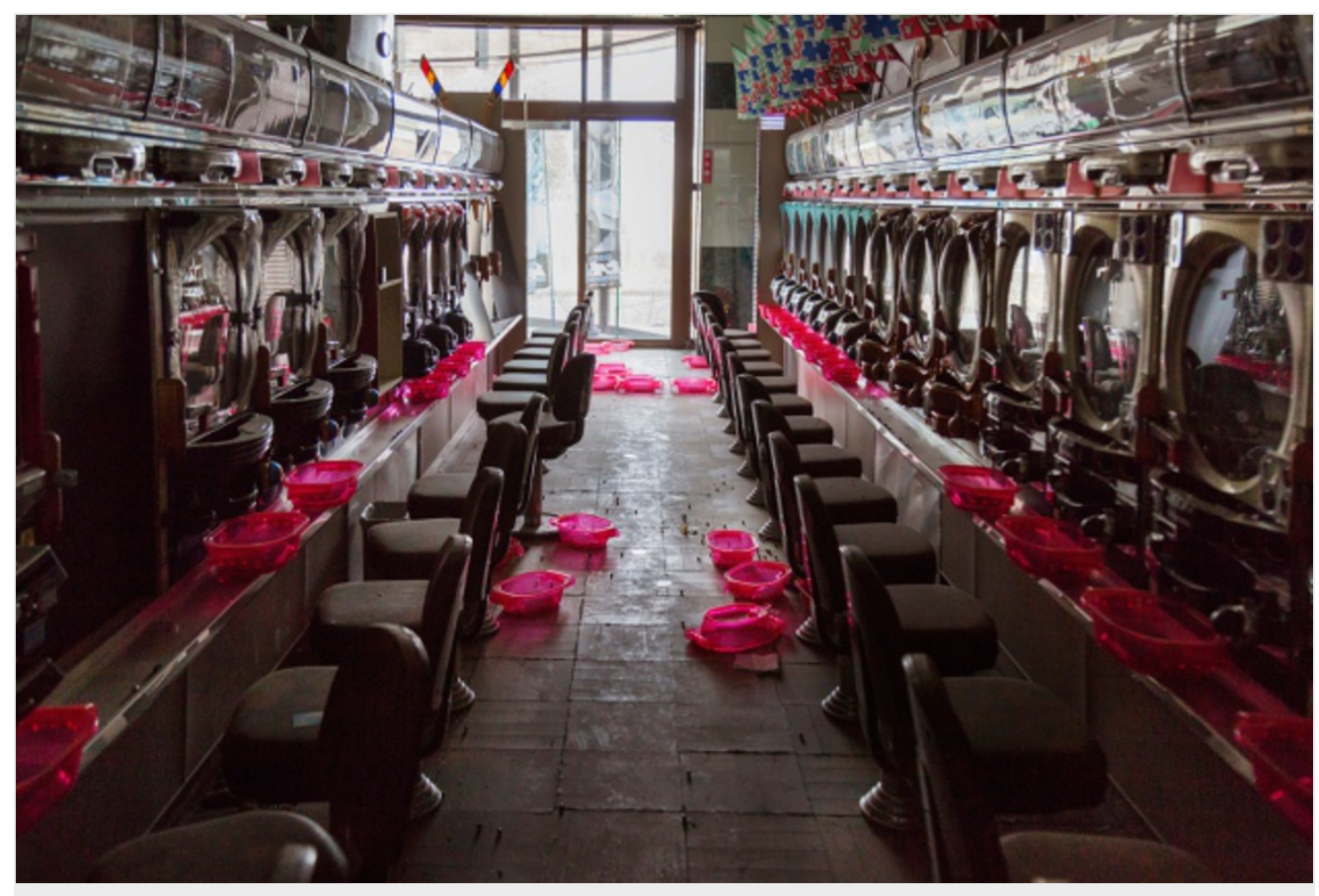

Ko Sasaki/New York Times/Reduxleyevine

Six years after the meltdown at Japan's Fukushima Daiichi nuclear power plant, much of the surrounding area is still deserted. The picture here - one of many shot by photographers visiting for the anniversary in March — shows a pachinko parlour (a type of gaming arcade) in Tomioka, where an evacuation order in place since the disaster will be partially lifted on 1 April.

\section{Snapping bloodsuckers}

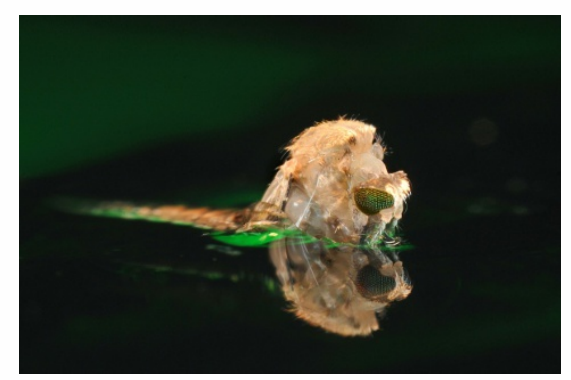

Jim Gathany has spent 30 years working for the US Centers for Disease Control and Prevention (CDC), photographing mosquitoes, lice, ticks and other creatures that carry diseases studied by its scientists. An exhibition of his work at the CDC Museum in Atlanta, Georgia, runs until 26 May and includes this shot of an Anopheles mosquito emerging from its pupal exoskeleton. 


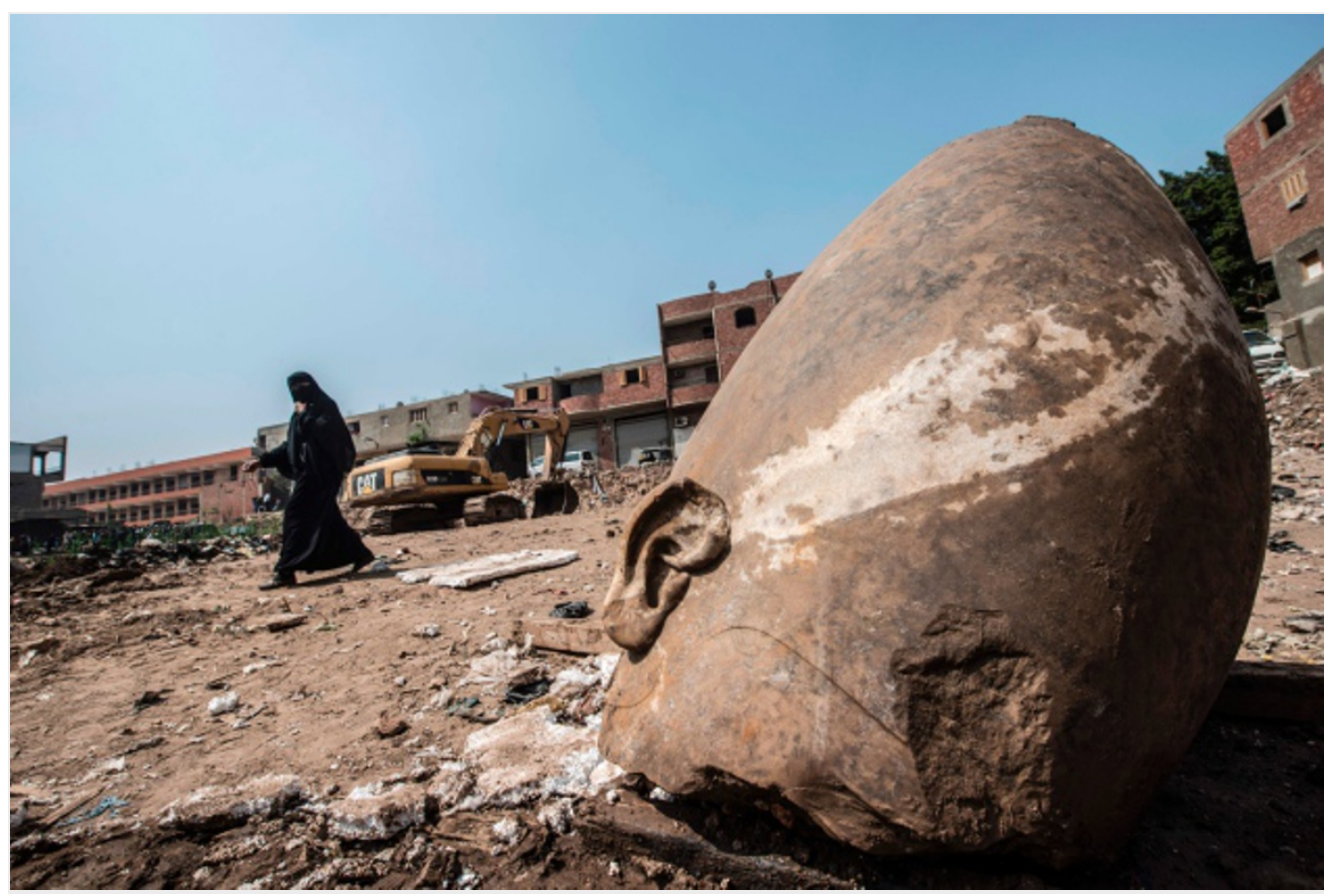

Khaled Desouki/AFP/Getty Images

Archaeologists in Egypt unearthed the remnants of a huge statue in Cairo this month. The relic may be a 3,000-year-old, 8-metre-tall representation of pharaoh Ramses II, also known as Ozymandias.

\section{Wellcome back}

The Wellcome Image Awards returns. This year's exhibition includes this visualization of data from 92,915 tweets containing the hashtag \#breastcancer, collected over an 8-week period.

Eric Clarke, Richard Amett and Jane Bums, Royal College of Surgeons in Ireland

\section{Ice and fire}

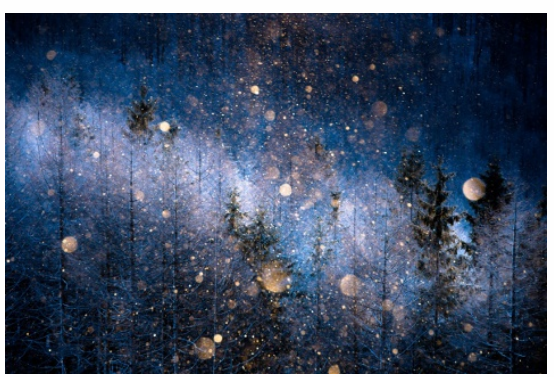


It took photographer Masayasu Sakuma four years of work to capture this picture of 'diamond dust' in a forest in Nagano prefecture, Japan. The elusive fog of ice particles occurs only a few times each year in this location. The shot was shortlisted in the Nature category of the open competition in the 2017 Sony World Photography Awards.

\section{Animals in action}

There were more than 48,000 submissions to the 14th Annual Smithsonian.com Photo Contest. This image of elephants on the banks of the Chobe River in Botswana was chosen as the winner of the Natural World category. The next Smithsonian contest is already open.

Nature | doi:10.1038/nature.2017.21754 